\title{
Physiological Traits of Thirty-Five Tomato Accessions in Response to Low Temperature
}

\author{
Sherzod Nigmatullayevich Rajametov ${ }^{+}\left[\right.$], Kwanuk Lee ${ }^{+}(\mathbb{D}$, Hyo-Bong Jeong, Myeong-Cheoul Cho, \\ Chun-Woo Nam and Eun-Young Yang *
}

National Institute of Horticultural \& Herbal Science, Rural Development Administration, Wanju 55365, Korea; sherzod_2004@list.ru (S.N.R.); kwanuk01@korea.kr (K.L.); bong9846@korea.kr (H.-B.J.); chomc@korea.kr (M.-C.C.); cwsky1004@daum.net (C.-W.N.)

* Correspondence: yangyang2@korea.kr; Tel.: +82-(0)63-238-6613; Fax: +82-(0)63-238-6605

+ Equal contribution.

Citation: Rajametov, S.N.; Lee, K.; Jeong, H.-B.; Cho, M.-C.; Nam, C.-W.; Yang, E.-Y. Physiological Traits of Thirty-Five Tomato Accessions in Response to Low Temperature. Agriculture 2021, 11, 792. https://doi.org/10.3390/ agriculture11080792

Academic Editor: Rachael Symonds

Received: 13 July 2021

Accepted: 17 August 2021

Published: 19 August 2021

Publisher's Note: MDPI stays neutral with regard to jurisdictional claims in published maps and institutional affiliations.

Copyright: (c) 2021 by the authors. Licensee MDPI, Basel, Switzerland. This article is an open access article distributed under the terms and conditions of the Creative Commons Attribution (CC BY) license (https:// creativecommons.org/licenses/by/ $4.0 /)$.
Abstract: Tomato is often exposed to diverse abiotic stresses and cold stress is one of harsh environmental stresses. Abnormal low temperature affects tomato growth and development, leading to, e.g., physiological disorders, flower drops, and abnormal fruit morphology, and causing a decrease in tomato yield and fruit quality. It is important to identify low temperature-(LT) tolerant tomato (Solanum lycopersicum L.) cultivars relying on different fruit types. In this study, our focus was to analyze the physiological traits of 35 tomato accessions with three different fruit types (cherry, medium, and large sizes) under night temperature set-points of $15^{\circ} \mathrm{C}$ for control temperature (CT) and $10^{\circ} \mathrm{C}$ for LT, respectively. Plant heights (PH) of most tomato accessions in LT were remarkably decreased compared to those in CT. The leaf length (LL) and leaf width (LW) were reduced depending on the genotypes under LT. In addition, the number of fruits (NFR), fruit set (FS), fruit yield (FY), and marketable yield (MY) were negatively affected in LT. The variation was further investigated by the correlation, the principal component (PCA), and the cluster analysis. Interestingly, positive correlations between different vegetative and reproductive traits were uncovered. Multivariate analysis including the PCA and hierarchical clustering classified the LT-treated 35 tomato accessions into four major groups. The identified accessions were associated with vegetative and reproductive parameters on positive directions. The results might be utilized for establishing breeding programs on selecting LT-tolerant tomato cultivars with different selection indices relying on fruit types during vegetative and/or reproductive stages.

Keywords: tomatoes; cold stress; fruit types; tomato breeding; principal component analysis; cluster analysis

\section{Introduction}

Tomato (Solanum lycopersicum L.) is the most essential horticultural vegetable in the world, providing vitamin A and C, rich minerals, low calories, lycopene, and $\beta$-carotene [1]. The importance of tomato crops has been gradually emerging due to increasing commercial, marketable, and dietary values [2]. The cultivated area of tomatoes is widely expanded among agricultural crops. According to Food and Agriculture Organization (FAO, http:/ / www.fao.org / faostat/ (accessed on 7 May 2021)) in 2019 and Korean Statistical Information Service (KOSIS, https: / / kosis.kr / eng / (accessed on 7 May 2021)) in 2021, the cultivated area and tomato production reached approximately 4.8 million hectares and 182 million metric tons in the world and around 6000 hectares and 40,020,000 metric tons in Korea, respectively. However, due to global warming and climate changes, the unpredictable agriculture weather, such as low and high temperatures, has critically limited the yields and the area of agricultural cultivation of tomato plants [3-5].

Tomato plant is one of sessile organisms, which experiences multiple abiotic stresses including cold stress, heat stress, high salinity stress, and drought stress during the pe- 
riods of vegetative and reproductive growth [6-8]. Low temperature (LT) is a critical factor for maintaining and improving the crop yield of tomato plants during the periods of growth and development stages [3,4]. LT $\left(0-20^{\circ} \mathrm{C}\right)$ above the freezing temperature (below $0{ }^{\circ} \mathrm{C}$ ) plays an important role in the leaf morphology [9], the truss appearance and growth [9-11], and the fruit development [12-15] during vegetative and reproductive stages. Recent studies have demonstrated that LT significantly influenced plant height $(\mathrm{PH})$, plant diameter $(\mathrm{PD})$, leaf length (LL), and leaf width $(\mathrm{LW})$ in vegetative parameters $[9,10,16,17]$ and flowering time (FT) $[16,18]$, the number of flowers (NFL) and fruits (NFR) $[18,19]$, fruit set (FS) [19], and fruit yield (FY) $[19,20]$ in reproductive parameters. Moreover, the relationships of the same traits during either vegetative or reproductive stages have been investigated, but the correlation of vegetative traits with reproductive traits remains unexplored under LT condition.

In Wanju, Korea, the maximum and minimum average temperatures have been ranging from $2.8-8.7^{\circ} \mathrm{C}$ and from $-6.3-0.2^{\circ} \mathrm{C}$ in the winter season since 1970 , respectively. Moreover, the average temperature has been ranging from $-1.7-3.9^{\circ} \mathrm{C}$ (https: / / www.weather.go.kr/w/index.do (accessed on 9 August 2021)). Due to such extreme and fluctuated low temperatures of the area in the winter season, the heating demand is dramatically increased at night time $[21,22]$ and the heating cost occupied approximately $20-30 \%$ of the managing cost of winter tomato cultivation from 2017-2019 [23]. The temperature control is one of the major considerable factors for the tomato cultivation in the winter greenhouse. Approximately $15{ }^{\circ} \mathrm{C}$ in the winter is maintained for the optimal temperature set-points, which provide tomatoes with conditions to grow healthy without severe cold stress $[9,24,25]$. The studies on the optimal temperature set-point have reported that the reduction of temperature by around $2{ }^{\circ} \mathrm{C}$ in greenhouse allowed to reduce around $16 \%$ of the winter heating cost for tomato cultivation $[16,26]$, implying that a reduction of temperature from $15^{\circ} \mathrm{C}$ to $10^{\circ} \mathrm{C}$ in winter greenhouse would lead to a significant decrease in the heating cost of tomato cultivation in agriculture. However, a few studies have dissected the relationship of winter tomato cultivation and night low temperature (NLT) $\left(10^{\circ} \mathrm{C}\right)$ in greenhouse $[4,16,21,22]$. It is reasonable that practical breeding programs for low temperature (LT)-tolerant tomato cultivars economically consider keeping low temperature $\left(10^{\circ} \mathrm{C}\right)$ during the night.

It is essential to utilize the large number of genotypes with various fruit types to provide proper indices to breeders for selecting LT-tolerant tomatoes. Although studies have been performed on the effect of LT on tomato plants with the large number of tomato genotypes [3,16,22], most have determined the impact of LT with limited genotypes [17,25]. In addition to this, only several studies have reported the selection criteria for LT-tolerant cultivars depending on fruit types [16,27]. Thus, it is still required to study the physiological aspects in response to LT with large-scale accessions and different fruit types of tomatoes.

In this work, we investigated the physiological traits of 35 tomato genotypes with different fruit types, which were grown in two different greenhouse conditions with night temperature set-points at $10{ }^{\circ} \mathrm{C}$ for low temperature (LT) and $15{ }^{\circ} \mathrm{C}$ for control treatment (CT), respectively, and analyzed the vegetative parameters of $\mathrm{PH}, \mathrm{SD} \mathrm{LL}$, and LW and the reproductive parameters of NFL, NFR, FS, FY, and MY with different fruit types through the correlation coefficient, PCA, and cluster analysis. This research would be helpful for understanding the relationships of multiple variables with vegetative and reproductive parameters and could be further utilized for breeding programs on selecting LT-tolerant tomato cultivars with different selection criteria relying on fruit types in greenhouse condition.

\section{Materials and Methods}

\subsection{Plant Material and Growth Conditions}

The plant material and growth conditions were followed as previously described in [18]. A total of 35 tomato breeding lines from the National Institute of Horticultural and Herbal Science (NIHHS, Wanju, Korea, $35^{\circ} 83^{\prime} \mathrm{N}, 127^{\circ} 03^{\prime} \mathrm{E}$ ) were used in this research 
(Table S1). All accessions were classified into two wild ( $<10 \mathrm{~g})$, twenty cherry (10-30 g), eleven medium (31-80 g), and two large ( $>81 \mathrm{~g})$ depending on fruit sizes [18]. The seeds of 35 accessions were sown on 31 August 2020 in plastic trays $(52 \times 26 \mathrm{~cm}$ in size, $6 \times 6 \mathrm{~cm}$ cells with pot volume $5 \mathrm{~L}$ ) containing 1:1 sand and commercial bed soil (Bio Sangto, Seoul, Korea) containing coco peat $(47.2 \%)$, peat moss $(35 \%)$, zeolite $(7 \%)$, vermiculite $(10.0 \%)$, dolomite $(0.6 \%)$, humectant $(0.006 \%)$, and fertilizers $(0.194 \%)$ containing $270 \mathrm{mg} \mathrm{kg}^{-1}$ of $\mathrm{N}, \mathrm{P}$, and $\mathrm{K}$, respectively. A liter of water was provided to each tray daily, and the trays were placed in a glasshouse $\left(26 / 18{ }^{\circ} \mathrm{C}\right.$ in day/night with relative humidity within $65-70 \%$ ). Seedlings with $20-25 \mathrm{~cm}$ height and first truss were transplanted on 28 October 2020. The seedlings were transferred into two plastic film greenhouses, where night temperature set-point was maintained at $15^{\circ} \mathrm{C}$ for 14 days in both greenhouses, adapting the seedlings to new environment conditions. Subsequently, night temperature set-point of each greenhouse was controlled for low temperature (LT) at $10{ }^{\circ} \mathrm{C}$ and control temperature (CT) at $15{ }^{\circ} \mathrm{C}$, respectively. Tomato seedlings of five plants per accession were planted with a plant distance of $140 \mathrm{~cm}$ by $40 \mathrm{~cm}$ between plants in both LT and CT greenhouses. All tomato accessions were randomly selected and planted with keeping the same arrangement of the accessions between LT and CT greenhouses.

The soil in two greenhouses were prepared according to the recommendations of the Korea Soil Information System (https:/ / soil.rda.go.kr (accessed on 1 November 2019)) equally with pre-plant broadcast manure at a dose of $1 \mathrm{~kg} \mathrm{~m}^{-2}$ and basal fertilizers containing $16 \mathrm{~g} \mathrm{~m}^{-2} \mathrm{~N}, 8 \mathrm{~g} \mathrm{~m}^{-2} \mathrm{~K}_{2} \mathrm{O}$, and $16 \mathrm{~g} \mathrm{~m}^{-2} \mathrm{P}_{2} \mathrm{O}_{5}$. In addition, the soil was regularly watered to avoid drought and weekly fertigated with solution A (N 5.5\%, K 4.5\%, Ca 4.5\%, B $0.00014 \%$, Fe $0.05 \%$, Zn 0.0001\%, Mo 0.0002\%) and B (N 6\%, P 2\%, K 4\%, Mg 1\%, B 0.05\%, Mn $0.01 \%$, Zn $0.005 \%$, Cu $0.0015 \%$ ), which were mixed in $1200 \mathrm{~L}$ of water (Mulpure, Daeyu Co. Ltd., Gyeongsan, Korea) [27].

The temperature was monitored in both $\mathrm{LT}$ and $\mathrm{CT}$ greenhouses during the periods of whole growth and development using a data logger (Figure S1A) (WatchDog 1450, Spectrum Technologies Inc., Aurora, CO, USA) and the climate data of the region was presented during the periods of tomato growth and development (Figure S1B). Night time temperature was maintained by a heating machine (Model TKP-800, Tae Kwang Machine Co. LTD., Daegu, Korea) when the temperature lowered below $10^{\circ} \mathrm{C}$ and $15^{\circ} \mathrm{C}$ and overall the relative humidity (RH) was approximately within $40 \%$ to $60 \%$ in both greenhouses, respectively.

The appearance of insects and diseases was observed daily and the chemicals were periodically applied to control them once every two weeks following the manufacturer's instructions. We used Jijon (Farmhannong, Korea, Spiromesifen 20\%) for the whitefly and the aphid with the dilution of 1:2000, Rampage (Hankooksamgong, Korea, Chlorofenapyr $5 \%$,) for the thrip with the dilution of 1:1000, Butina (Farmhannong, Korea, Iminoctadine tris $30 \%$ ) for the leaf mold and the gray mold, with the dilution of 1:1000, and Deomani (Farmhannong, Korea, Polyoxin B 50\%) for the powderly mildew and the fungi with the dilution of 1:5000.

\subsection{Data collection on Vegetative and Reproductive Growth}

The vegetative parameters of plant height $(\mathrm{PH})$, leaf length (LL), leaf width (LW), and stem diameter (SD) were measured using 70-d-old plants after transplanting (DAT) from five plants per accession in both greenhouses. The reproductive parameters of the number of flowers (NFL), the number of fruits (NFR), fruit set (FS), fruit yield (FY), marketable yield (MY), and output of marketable yield (OMY) were evaluated by calculating from the third to six trusses of each plant. Differences in FS and FY parameters between plants grown in LT and CT greenhouses were calculated by subtracting the index of FS and FY of CT from LT, respectively [16]. Fruit set (FS, \%) with diameter $\geq 0.5 \mathrm{~cm}$ was calculated as follows [28]: Fruit set $(\%)=($ The number of fruits $/$ The number of flowers $) \times 100$. Fruit yield (FY) was determined by the sum of fresh weight (FW) in $\mathrm{kg}$ of all fruits harvested from the third to sixth trusses from five individual plants. 


\subsection{Data Analysis}

The significance of difference in vegetative parameters of $\mathrm{PH}, \mathrm{SD}, \mathrm{LL}$, and $\mathrm{LW}$, and reproductive parameters of NFL, NFR, FS, TY, MY, and OMY under LT and CT was assessed as described in the figure legends with Student's $t$-test and the analysis of correlation coefficients was performed among the total population $(n=35)$ for correlation coefficient with EXCEL 2016 (Microsoft, WA, USA). Principal components analysis (PCA) was implemented using SPSS (IBM SPSS v27.0., Chicago, IL, USA) to study the sample patterns and cluster analysis. The adequacy of the samples was tested by The Kasier-Meyer-Olkin (KMO) and the Bartlett's test of Sphericity (BTS) was conducted to estimate the relationship between variables.

\section{Results}

\subsection{The Analysis of the Vegetative Traits with Different Fruit Type}

To study the vegetative traits including plant height (PH), stem diameter (SD), leaf length (LL), and leaf width (LW) of tomato plants under LT condition, we analyzed 35 tomato accessions with different fruit types classified into wild, cherry, medium, and large fruit size (Table S1). The PH of most tomato accessions in LT were remarkably reduced at 70 days after transplanting (DAT) compared to those in CT except for T32 accession in medium size (Figure 1A), while SD in LT were not significantly different from those in CT except for T21 accession in cherry size (Figure 1B). Next, the LL and LW were investigated at $70 \mathrm{DAT}$ and 25 tomato accessions decreased under LT, whereas 10 tomato accessions including T04, T07, T09, T12, T13, T19, and T22 in cherry size, T28 and T31 in medium size, and T35 in large size were not significantly influenced by LT (Figure 2A,B).

\subsection{The Analysis of the Reproductive Traits with Different Fruit Type}

The reproductive traits including the number of flowers (NFL), the number of fruits (NFR), fruit set (FS), fruit yield (FY), and marketable yield (MY) were evaluated among 35 tomato accessions under LT and CT conditions. The NFL of T04 and T20 accessions in LT positively increased, whereas the NFL of T15, T29, and T31 accessions in LT negatively decreased compared to that in the CT condition (Figure 3A). The NFR was also assessed among 35 tomato populations. Only the T11 accession in cherry type increased more in LT than that in CT, whereas the NFR of 2 genotypes (T01 and T02) in wild, 13 genotypes (T04, $\mathrm{T} 08, \mathrm{~T} 09, \mathrm{~T} 10, \mathrm{~T} 14, \mathrm{~T} 15, \mathrm{~T} 16, \mathrm{~T} 17, \mathrm{~T} 18, \mathrm{~T} 19, \mathrm{~T} 20, \mathrm{~T} 21$, and T22) in cherry size, 4 genotypes (T27, T30, T31, and T33) in medium size, and 1 genotype (T35) in large size under LT were remarkably reduced compared to that in CT (Figure 3B). On the other hand, the NFR of 7 genotypes (T03, T05, T06, T07, T12, and T13) in cherry type, 7 genotypes (T23, T24, T25, T26, T28, T29, and T32) in medium, and 1 genotype (T34) in large type were identified with no significant difference between LT and CT conditions (Figure 3B). In addition, the fruit set (FS) ratio was calculated with all tomato accessions. Interestingly, the FS of only the T11 accession in cherry type was significantly higher in LT compared with that in CT (Figure 3C). In contrast to this, the FS of 2 genotypes (T01 and T02) in wild, 15 genotypes (T04, T07, T08, T09, T10, T12, T14, T15, T16, T17, T18, T19, T20, and T21, T22) in cherry type, 3 genotypes (T27, T30, and T31) in medium type, and 2 genotypes (T34 and T35) in large type under LT dramatically decreased compared to those in CT (Figure 3C). However, the FS of 4 genotypes (T03, T05, T06, and T13) in cherry type and 7 genotypes (T23, T24, $\mathrm{T} 25, \mathrm{~T} 26, \mathrm{~T} 28, \mathrm{~T} 29$, and T32) in medium type were not observed with significant difference in both LT and CT conditions.

In order to estimate the fruit marketability, the reproductive traits including fruit yield (FY), marketable yield (MY), and output marketable fruit (OMF) were determined among 35 tomato accessions. The FY and MY were drastically reduced in 8 genotypes (T04, T05, T08, T09, T15, T16, T18, and T21) in cherry type, 5 genotypes (T23, T25, T27, T31, and T33) in medium type, and 2 genotypes (T34 and T35) in large type under LT compared to $\mathrm{CT}$, whereas the FY of T24 in medium type was noticeably increased under LT (Figure 4A,B). It was remarkable that the OMF over 60\% between LT and CT was 
observed in 4 genotypes (T05, T17, T19 and T20) in cherry type, 4 genotypes (T23, T25, T28, and T32) in medium type, and 1 genotype (T34) in large type, whereas the OMF of 6 genotypes (T06, T07, T11, T14, T20 and T22) in cherry type and 4 genotypes (T28, T29, T30 and T32) in medium type were observed with no significant difference (Figure 4C). Subsequently, we compared the difference in FS ratio between CT and LT. The difference of FS exhibited that T06, T11, T13, T23, T24, and T29 were positively influenced under LT condition. The most positive differences over $20 \%$ were observed in T13 $(21.0 \%)$ and $\mathrm{T} 11(52.1 \%)$, and the most negative differences below $50 \%$ were found in T09 $(-51.5 \%)$, T20 $(-60.5 \%)$, and T04 $(-64.0 \%)$ (Figure S2A). The difference in FY in LT showed that the most positive difference over $0 \mathrm{~kg}$ was observed in T24 $(0.15 \mathrm{~kg}), \mathrm{T} 02(0.08 \mathrm{~kg})$, and T11 $(0.05 \mathrm{~kg})$, while the most negative difference below $1.0 \mathrm{~kg}$ was found in T31 $(-1.48 \mathrm{~kg}), \mathrm{T} 15$ $(-1.37 \mathrm{~kg})$, T35 $(-1.26 \mathrm{~kg})$, T30 $(-1.22 \mathrm{~kg})$, and T34 $(-1.09 \mathrm{~kg})$ (Figure S2B).

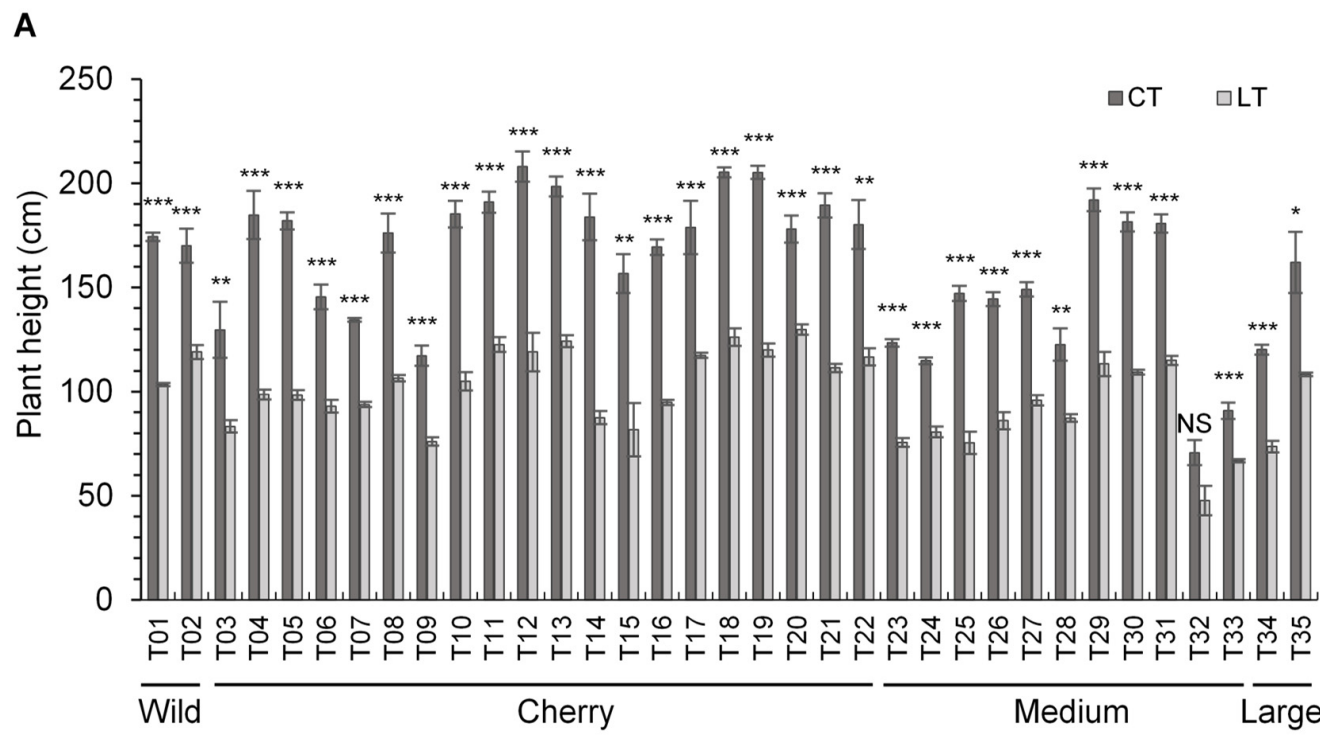

B

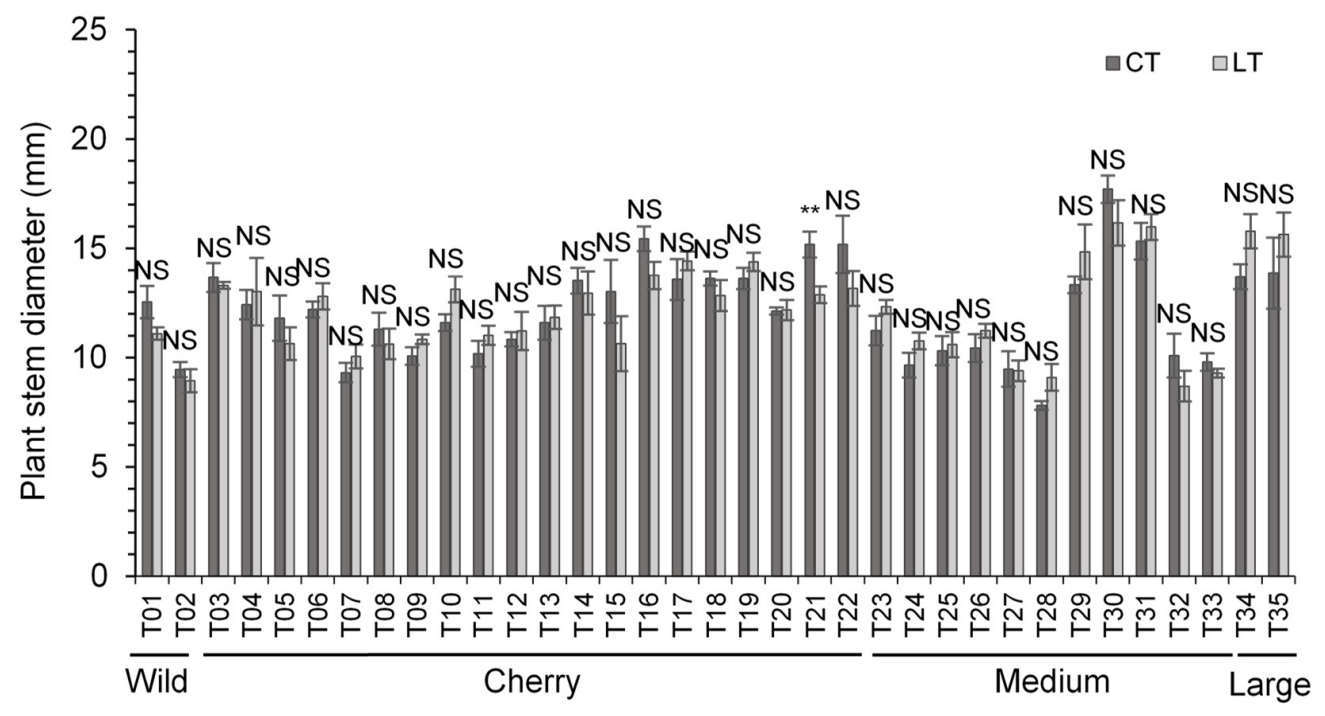

Figure 1. The analysis of vegetative traits on (A) plant height and (B) plant stem diameter among 35 tomato accessions with different fruit types under CT and LT greenhouses. Plant height and stem diameter were measured at 70 days after transplanting. Significant differences were evaluated with Student's $t$-test $(p \leq 0.05, p \leq 0.01$, and $p \leq 0.001)$ and are denoted by ${ }^{*}, * *$, and ${ }^{* * *}$, respectively. NS indicates not significant and bars indicate \pm standard deviation $(n=5)$. 
A
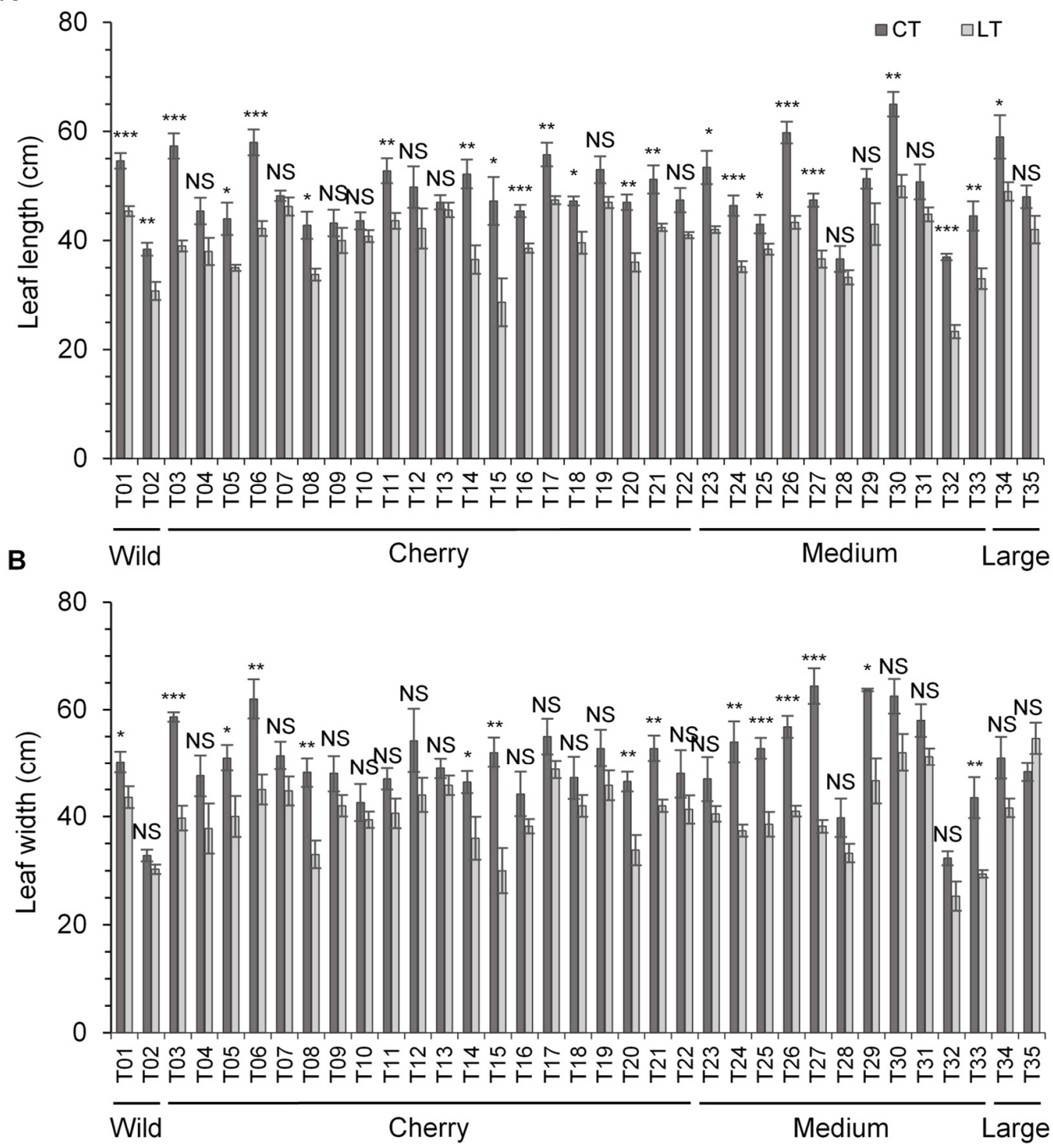

Figure 2. The analysis of vegetative traits on (A) leaf length and (B) leaf width among 35 tomato accessions with different fruit types under CT and LT greenhouses. Leaf length and width were measured at 70 days. Significant differences were evaluated with Student's $t$-test $(p \leq 0.05, p \leq 0.01$, and $p \leq 0.001)$ and are denoted by ${ }^{*}{ }^{* *}$, and ${ }^{* *}$, respectively. NS indicates not significant and bars indicate \pm standard deviation $(n=5)$.

\subsection{The Principal Component Analysis (PCA) of Physiological Traits}

In order to approach the multivariate analysis, the principal component analysis (PCA) was performed together with the correlation matrix of nine variables measured under LT conditions (Figure S3). The Kaisere-Meyere-Olkin (KMO) for sampling adequacy on vegetative and reproductive score data was 0.643 in LT. Bartlett's Test of Sphericity (BTS) was significantly lower than 0.001 . The first three principal components showed that the eigenvalues were greater than 1 (Table S2). Total variance of the data was explained with the $67.65 \%$ which were composed of $41.02 \%$ from component factor 1 (PC1) and $26.63 \%$ from component 2 (PC2), respectively, and the traits (scores $>0.30$ ) were loaded onto PC1 and PC2 (Table S2). PC1 and PC2 were clearly separate from vegetative and reproductive parameters with positive trends (Figure 5). PC1 was primarily combined with vegetative parameters (LL, LW, and SD) and PC2 was associated with reproductive parameters (FS, NFR, and FY). 

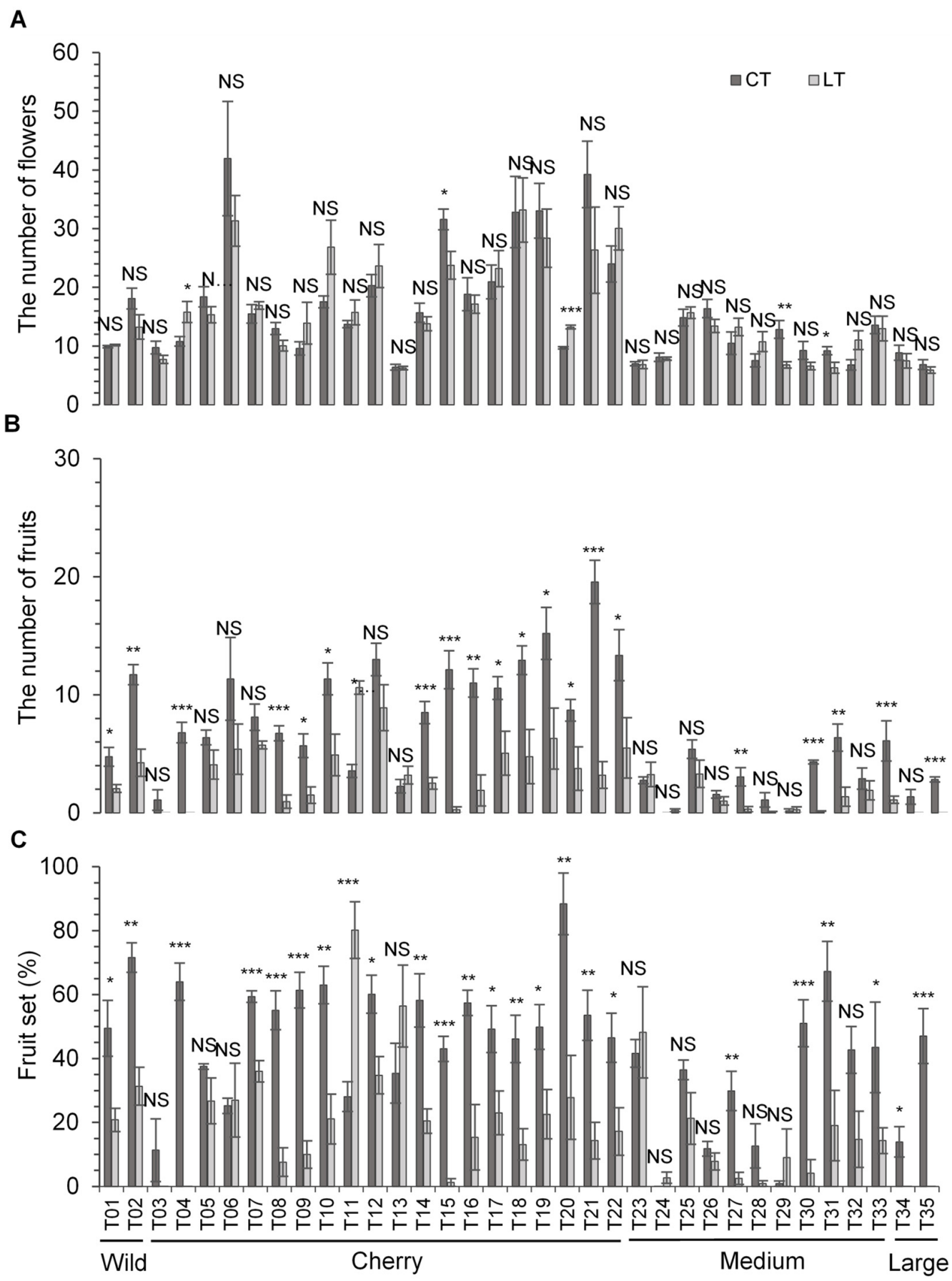

Figure 3. The analysis of reproductive traits on (A) the number of flowers, (B) the number of fruits, and (C) fruit set among 35 tomato accessions with different fruit types under CT and LT greenhouses. Significant differences were evaluated with Student's $t$-test $(p \leq 0.05, p \leq 0.01$, and $p \leq 0.001)$ and are denoted $b y^{*}, * *$, and $* * *$, respectively. NS indicates not significant and bars indicate \pm standard deviations $(n=5)$.

\subsection{Clustering Analysis}

A score plot was obtained using the component factor 1 and factor 2 in LT, displaying 35 tomato accessions with different fruit types (Figure 5). The factors were further subjected to hierarchical cluster analysis using the Euclidean distance matrix via Ward's method of agglomeration (Figure 6). Based on the dendrogram result, four major groups were observed in LT. The cluster 2 consisted of vegetative parameters related to SD, LL, and LW and the cluster 3 was associated with reproductive parameters related to NFR, FS, and FY. 

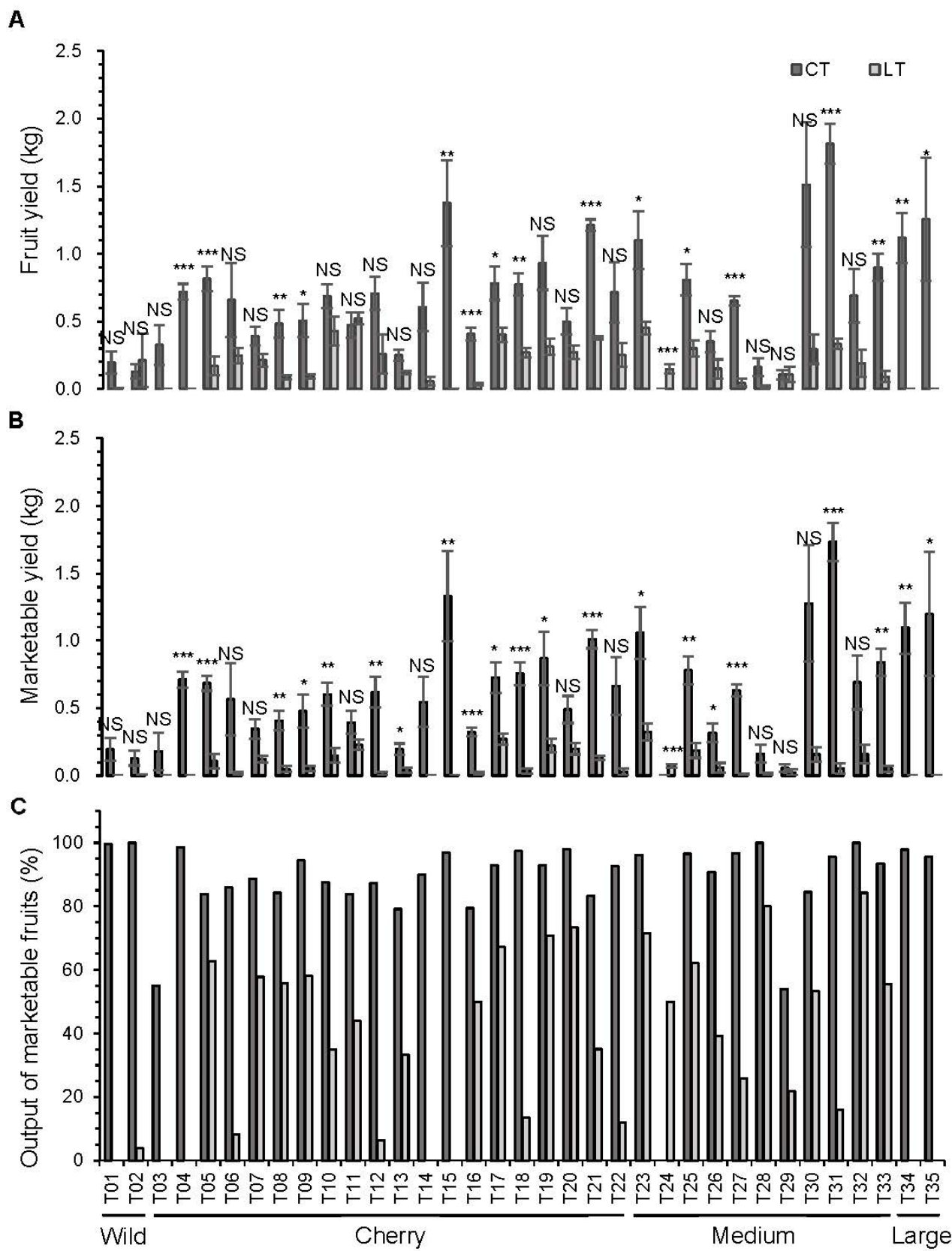

Figure 4. The analysis of reproductive traits on (A) fruit yield, (B) marketable yield, and (C) output of marketable fruit among 35 tomato accessions with different fruit types in CT and LT greenhouses. Significant differences were evaluated with Student's $t$-test $(p \leq 0.05, p \leq 0.01$, and $p \leq 0.001)$ and are denoted $b y^{*}, * *$, and ${ }^{* * *}$, respectively. NS indicates not significant and bars indicate \pm standard deviation $(n=5)$. 


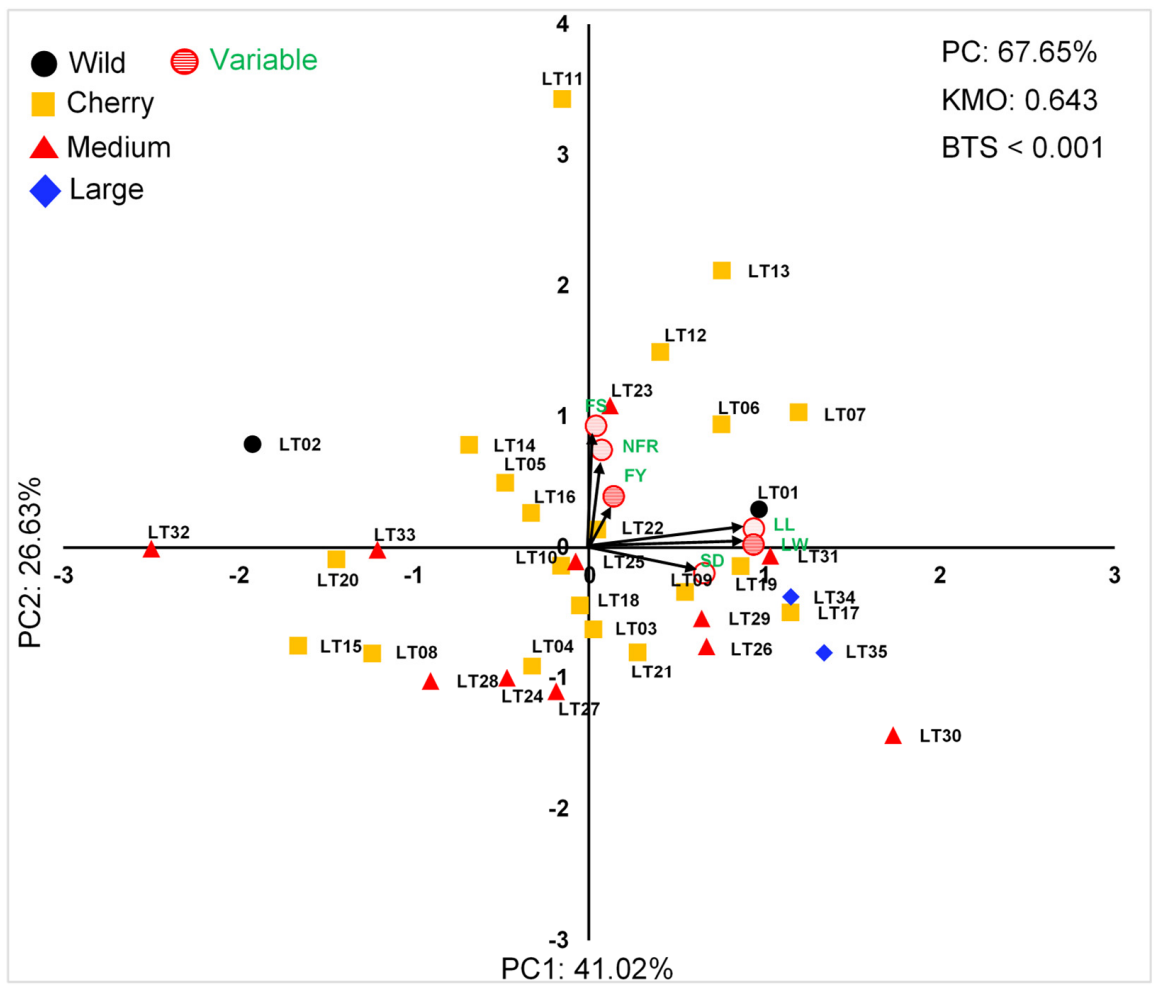

Figure 5. Biplot for the first two principal components (PC1 and PC2) was shown using the principal component analysis (PCA) with 6 physiological traits and 35 tomato accessions depending on fruit types including wild (black round circle), cherry (yellow square), medium (red triangle), and large (blue diamond) fruits under LT condition. The red round circle with horizontal lines and the arrow indicate the variables and the direction of vectors, respectively. Leaf width (LW), leaf length (LL), stem diameter (SD), number of fruits (NFR), fruit setting (FS), and fruit yield (FY).

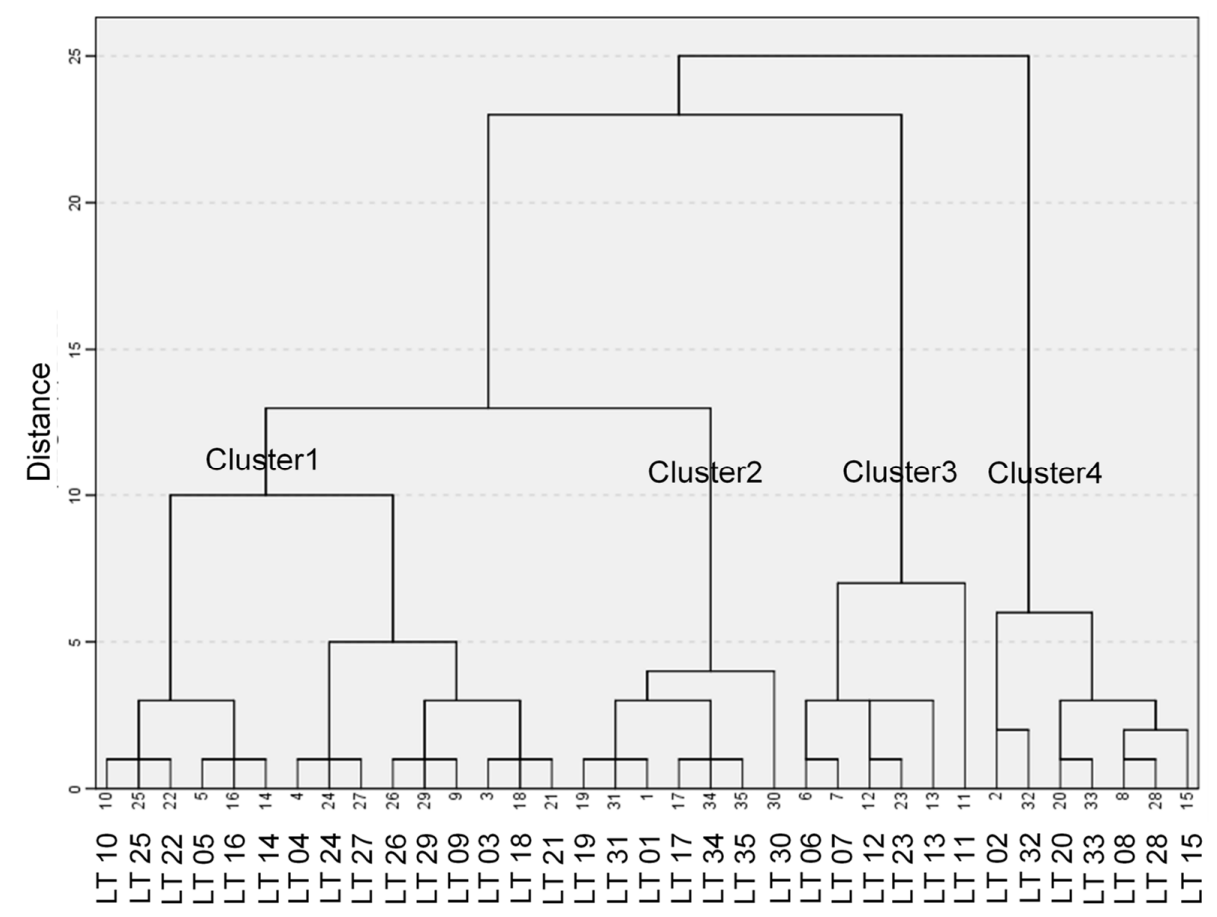

Figure 6. Dendrogram was exhibited by the cluster analysis of 35 tomato accessions based on the Euclidean distance using components factors 1 and factors 2 under LT condition. 


\section{Discussion}

Tomato plants have evolved against adverse environment factors and current tomato plants harbor several mechanisms to overcome cold stress [29-33]. Previous studies have mainly focused on the response to low temperature stress with limited genotypes and fruit types as well as a short period of the treatment during specific growth stages $[11,17,25,34]$. Moreover, recent studies have not been reported in regards to night low temperature (NLT) which can save the heating costs of the tomato cultivation in winter greenhouse. In this study, we assessed the vegetative and reproductive traits of 35 tomato accessions with different fruit types during whole plant growth stages under NLT.

LT noticeably influenced vegetative traits including $\mathrm{PH}, \mathrm{LL}$, and $\mathrm{LW}$ in tomato plants at 70 DAT compared to CT. In particular, the effect of LT on the PH in LT condition resulted in a significant decrease in most accessions except for one accession, T32, for which there was no significant difference between the LT and CT conditions (Figure 1A). Previous studies have shown that the growth of tomato plants is significantly retarded in LT conditions as shown in this study $[3,21,22,25]$. Moreover, the researchers showed that the inhibited growth of $\mathrm{PH}$ results from a decrease in the number of leaves $[35,36]$. It is of interest to further investigate the correlation of $\mathrm{PH}$ and the number of tomato leaves between LT-tolerant and-sensitive cultivars. The effect of LT on LL and LW in LT exhibits that the growth inhibited $100 \%$ and 50\% of accession in wild, $60 \%$ and $40 \%$ accession in cherry types, and $50 \%$ accession and $0 \%$ accession in large types, respectively (Figure 2). In line with our results, previous studies have also demonstrated that LT-treated plants lead to a reduction in leaf area and the decreased leaf area ratio which influences the decrease in relative growth rate by lowering photosynthesis [21,22,37]. Next, our important endeavor is to determine how photosynthetic parameters including chlorophyll contents and gas exchange rates are associated with LL and LW in LT-tolerant and -sensitive cultivars within the same fruit types or different fruit types. Intriguingly, our result shows that LT did not affect the SD of most accessions (Figure 1B). The result is inconsistent with a previous study which has determined the difference in the SD of tomato plants under LT and $\mathrm{CT}$ conditions. On the other hand, a report supported that a minimum temperature around $-2{ }^{\circ} \mathrm{C}$ to $-4{ }^{\circ} \mathrm{C}$ results in no stem diameter difference in woody plants, whereas a minimum temperature around $-5^{\circ} \mathrm{C}$ to $-6^{\circ} \mathrm{C}$ causes the reduction of stem diameter [38]. The minimum temperature in our previous research was lower by around $3{ }^{\circ} \mathrm{C}$ until 10 weeks than that in this study [16]. Studies on SD of tomato plants have not been reported under LT conditions. Further studies are necessary to determine low temperature set points affecting the stem diameter in tomato plants.

We evaluated the reproductive parameters including NFL, NFR, and FS in LT and CT. Previous reports have determined the increased NFL in declining average temperature during $24 \mathrm{~h} \mathrm{[20],} \mathrm{day} \mathrm{temperature} \mathrm{[19],} \mathrm{and} \mathrm{night} \mathrm{temperature} \mathrm{[39].} \mathrm{However,} \mathrm{a} \mathrm{study}$ revealed that NFL in the first truss was not influenced by air temperature, whereas the NFL was increased by low root temperature [40]. Moreover, our previous study exhibits that the increased NFL and decreased NFL result from a genotype-specific interaction with LT [16]. Our current result shows that LT did not affect NFL in most accessions (Figure 3A), except that the NFL of two and three accessions was increased and decreased under LT, respectively (Figure 3A). Although we do not know the exact mechanistic function of the effect of LT on NFL, our finding with previous results imply that the effect of low air temperature on NFL was not notably influenced in our study. Further studies are required to determine how air and root low temperature impact on NFL with fruit types. Previous studies have shown that NFR and FS play an important role in determining LT tolerant-tomato cultivars, because NFR and FS are highly related to FY [16,35]. Similarly, our results show that the effect of LT on NFR led to a reduction in $70.0 \%$ of cherry type and $36.36 \%$ of medium type, respectively (Figure 3B). As well, FS also led to a reduction in $80 \%$ of cherry type and $36.36 \%$ of medium type in LT (Figure 3C), showing that NFR is closely correlated with the FS. Moreover, our findings reveal that both NFR and FS are associated with FY (Supplementary Figure S3). Considering that the NFLs were not 
different in most accessions regardless of fruit types, the poor quality of flower pollens in LT might influence the decreased FS among the accessions $[12,18,20]$, but the reduced FS might be not influenced by ovule viability and/or stigma level [41]. Furthermore, the effect of LT resulted in the significantly declined FY and MY, regardless of fruit type (Figure 4). A previous research has demonstrated that the effect of LT reduces FY due to the reduced number of pollens, the reduced pollen germination rate, aborted pollens, and the malformation of pollen tube which affect FS later on $[18,20]$. Although we cannot completely rule out the involvement of ovule and stigma development in FS and FY, next, it is worth determining the mechanistic role of pollen germination and pollen grain viability involved in fruit set and fruit development in response to LT. Collectively, our aforementioned results suggest that the impact of LT on vegetative and reproductive traits may be associated with the effect of genotype, not with fruit types.

Previous researches have been determined the traits during vegetative or reproductive stage in LT and the question of how the vegetative growth is associated with fruit yield remains unanswered. We applied the correlation matrix of vegetative and reproductive traits to the PCA analysis [42]. The first two PCA analyses explained $41.02 \%$ and $26.63 \%$ of the total physiological variables among 9 traits determined in LT. Six traits (with score $>0.30$ ) were loaded onto PC1 and PC2 (Table S2). Our finding showed that the angle between the vectors of traits including LL, LW, and SD in PC1 and NFR, FY, and FS in PC2 are lower than $90^{\circ}$. The vegetative and reproductive traits are positively correlated to some extent and the FY is strongly correlated with NFR and FS. In line with our results, previous researches have shown that the effect of LT on reproductive traits led to the reduction in NFR and FS, together with FY, indicating that these traits are positively associated with LT [20]. Moreover, a study reported that seed germination and vegetative growth of tomato are not correlated under cold stress, which suggests that each growth and development stage should be selected and assessed for plant breeding [11]. It is therefore likely that FY in LT is not strongly connected with vegetative traits. Subsequently, the biplot analysis was further drawn to assess the multivariate relationship among 35 tomato accessions and it displayed that 35 tomato genotypes are not grouped with fruit types (Figure 5). Rather, the accessions are sporadically located in a plot regardless of fruit types. This might result from the tomato accessions that possess the genetic diversity within the same fruit type [43]. Moreover, the cluster analysis exhibited four major clusters (Figure 6) and the cluster 1 and 4 tended to be negatively involved in vegetative and reproductive traits and/or be less associated with them on positive trends. The cluster 2 and 3 showed vegetative (SD, LL, and LW) and reproductive parameters (NFR, FS, and FY) with positive directions, respectively. Interestingly, 5 out of 6 were cherry type in cluster 3 , but different fruit types were grouped in cluster 2, implying that cherry types in cluster 3 , with the consideration of reproductive parameters, are more tolerant to LT than other accessions. Although we cannot completely exclude a possibility that the results from the PCA and clustering analysis might be influenced by some secondary symptoms of LT stress response, the selected genotypes in cluster 2 and 3 could be further utilized for the breeding program to select LT-tolerant tomatoes with the parameters in the greenhouse.

\section{Conclusions}

The current study has determined the physiological traits of thirty-five tomato accessions with different fruit types in the response to night low temperature, which is economically important for the tomato cultivation in winter greenhouse. Based on correlation coefficient, PCA, and cluster analysis, some accessions were closely involved in vegetative and/or reproductive parameters depending on genotypes. Future researches will be required to evaluate more accessions of large fruit type in LT and the selected accessions will have to be used for the determination of physiological and molecular functions, combined with DNA- and RNA-seq. 
Supplementary Materials: The following are available online at https:/ / www.mdpi.com/article/10 .3390 /agriculture11080792/s1, Figure S1: Air temperature was measured in LT and CT greenhouse during the period of tomato growth and development, respectively. Figure S2: The analysis of difference in FS and FY among 35 tomato accessions in LT and CT. Figure S3: The correlations coefficients between vegetative and reproductive traits in total population of tomatoes in LT, Table S1: Tomato accessions for the evaluation of physiological traits against low temperature in winter 2020-2021. Table S2: Loading matrix associated with the principal components analysis (PCA) for 9 physiological traits.

Author Contributions: Conceptualization, M.-C.C. and E.-Y.Y.; methodology, S.N.R., M.-C.C., C.-W.N. and E.-Y.Y.; investigation, S.N.R., K.L., H.-B.J. and E.-Y.Y.; writing-original draft preparation, S.N.R. and K.L.; writing-review and editing, S.N.R., K.L. and E.-Y.Y.; visualization, S.N.R. and K.L.; supervision, M.-C.C. All authors have read and agreed to the published version of the manuscript.

Funding: This study was supported by a grant (Project No: PJ01266202 “Breeding and selection of tomato lines with tolerance to abnormal temperatures") from the National Institute of Horticultural and Herbal Science, Rural Development Administration.

Institutional Review Board Statement: Not applicable.

Informed Consent Statement: Not applicable.

Data Availability Statement: The datasets presented in this study are available upon request to the corresponding author.

Conflicts of Interest: The authors declare no conflict of interest.

\section{References}

1. Willcox, J.K.; Catignani, G.L.; Lazarus, S. Tomatoes and Cardiovascular Health. Crit. Rev. Food Sci. Nutr. 2003, 43, 1-18. [CrossRef] [PubMed]

2. Kimura, S.; Sinha, N. Tomato (Solanum lycopersicum): A Model Fruit-Bearing Crop. Cold Spring Harb. Protoc. 2008. [CrossRef]

3. Van Ploeg, D.; Heuvelink, E. Influence of sub-optimal temperature on tomato growth and yield: A review. J. Hortic. Sci. Biotechnol. 2005, 80, 652-659. [CrossRef]

4. De Koning, A.N.M. The effect of different day/night temperature regimes on growth, development and yield of glasshouse tomatoes. J. Hortic. Sci. 1988, 63, 465-471. [CrossRef]

5. Ro, S.; Chea, L.; Ngoun, S.; Stewart, Z.P.; Roeurn, S.; Theam, P.; Lim, S.; Sor, R.; Kosal, M.; Roeun, M. Response of Tomato Genotypes under Different High Temperatures in Field and Greenhouse Conditions. Plants 2021, 10, 449. [CrossRef]

6. Theocharis, A.; Clément, C.; Barka, E.A. Physiological and molecular changes in plants grown at low temperatures. Planta 2012, 235, 1091-1105. [CrossRef]

7. Shinozaki, K.; Yamaguchi-Shinozaki, K. Molecular responses to dehydration and low temperature: Differences and cross-talk between two stress signaling pathways. Curr. Opin. Plant Biol. 2000, 3, 217-223. [CrossRef]

8. Wang, W.-X.; Vinocur, B.; Altman, A. Plant responses to drought, salinity and extreme temperatures: Towards genetic engineering for stress tolerance. Planta 2003, 218, 1-14. [CrossRef]

9. Hoek, I.; Cate, C.H.H.T.; Keijzer, C.J.; Schel, J.H.; Dons, H.J. Development of the Fifth Leaf is Indicative for Whole Plant Performance at Low Temperature in Tomato. Ann. Bot. 1993, 72, 367-374. [CrossRef]

10. Venema, J.H.; Posthumus, F.; De Vries, M.; Van Hasselt, P.R. Differential response of domestic and wild Lycopersicon species to chilling under low light: Growth, carbohydrate content, photosynthesis and the xanthophyll cycle. Physiol. Plant. 1999, 105, 81-88. [CrossRef]

11. Foolad, M.; Lin, G. Relationship between Cold Tolerance during Seed Germination and Vegetative Growth in Tomato: Germplasm Evaluation. J. Am. Soc. Hortic. Sci. 2000, 125, 679-683. [CrossRef]

12. Picken, A.J.F. A review of pollination and fruit set in the tomato (Lycopersicon esculentum Mill.). J. Hortic. Sci. 1984, 59, 1-13. [CrossRef]

13. Adams, S.R.; Cockshull, K.E.; Cave, C.R.J. Effect of Temperature on the Growth and Development of Tomato Fruits. Ann. Bot. 2001, 88, 869-877. [CrossRef]

14. Sawhney, V.K.; Polowick, P.L. Fruit development in tomato: The role of temperature. Can. J. Bot. 1985, 63, 1031-1034. [CrossRef]

15. Hurd, R.G.; Graves, C.J. Some effects of air and root temperatures on the yield and quality of glasshouse tomatoes. J. Hortic. Sci. 1985, 60, 359-371. [CrossRef]

16. Sherzod, R.; Yang, E.Y.; Cho, M.C.; Chae, S.Y.; Kim, J.H.; Nam, C.W.; Chae, W.B. Traits Affecting Low Temperature Tolerance in Tomato and Its Application to Breeding Program. Plant Breed. Biotechnol. 2019, 7, 350-359. [CrossRef]

17. Xiaoa, F.; Yang, Z.; Zhua, L. Low temperature and weak light affect greenhouse tomato growth and fruit quality. J. Plant Sci. 2018, $6,16-24$. 
18. Wittwer, S. Cold exposure of tomato seedlings and flower formation. Proc. Amer. Soc. Hort. Sci. 1956, 67, 369-376.

19. Rylski, I. Fruit set and development of seeded and seedless tomato fruits under diverse regimes of temperature and pollination. $J$. Am. Soc. Hortic. Sci. 1979, 104, 835-838.

20. Ercan, N.; Vural, H. The effects of low temperatures on fruit set of tomatoes. Acta Hortic. 1994, 336, 65-72. [CrossRef]

21. Smeets, L.; Garretsen, F. Growth analyses of tomato genotypes grown under low night temperatures and low light intensity. Euphytica 1986, 35, 701-715. [CrossRef]

22. Nieuwhof, M.; Garretsen, F.; Van Oeveren, J. Growth analyses of tomato genotypes grown under low energy conditions. Neth. J. Agric. Sci. 1991, 39, 191-196. [CrossRef]

23. Rural Development Administration (RDA). Data Book of Agricultural Products Income for the Improvement of Agricultural Management in 2019; Rural Development Administration: Jeonju, Korea, 2020.

24. Paul, E.M.M.; Hardwick, R.C.; Parker, P.F. Genotypic Variation in the Response to Sub-Optimal Temperatures of Growth in Tomato (Lycopersicon Esculentum Mill.). N. Phytol. 1984, 98, 221-230. [CrossRef]

25. Franco, T. Effects of Stressful and Unstressful Low Temperature on Vegetable Crops: Morphological and Physiological Aspects. Acta Hortic. 1991, 287, 67-76. [CrossRef]

26. Elings, A.; Kempkes, F.; Kaarsemaker, R.; Ruijs, M.; Van De Braak, N.; Dueck, T. The Energy Balance and Energy-Saving Measures in Greenhouse Tomato Cultivation. Acta Hortic. 2005, 691, 67-74. [CrossRef]

27. Yang, E.-Y.; Rajametov, S.; Cho, M.-C.; Jeong, H.-B.; Chae, W.-B. Factors Affecting Tolerance to Low Night Temperature Differ by Fruit Types in Tomato. Agriculture 2021, 11, 681. [CrossRef]

28. Abdul-Baki, A.A. Tolerance of Tomato Cultivars and Selected Germplasm to Heat Stress. J. Am. Soc. Hortic. Sci. 1991, 116, 1113-1116. [CrossRef]

29. Zhang, X.; Fowler, S.G.; Cheng, H.; Lou, Y.; Rhee, S.Y.; Stockinger, E.J.; Thomashow, M.F. Freezing-sensitive tomato has a functional CBF cold response pathway, but a CBF regulon that differs from that of freezing-tolerant Arabidopsis. Plant J. 2004, 39, 905-919. [CrossRef]

30. Goodstal, F.J.; Kohler, G.R.; Randall, L.B.; Bloom, A.J.; St.Clair, D.A. A major QTL introgressed from wild Lycopersicon hirsutum confers chilling tolerance to cultivated tomato (Lycopersicon esculentum). Theor. Appl. Genet. 2005, 111, 898-905. [CrossRef]

31. Chinnusamy, V.; Zhu, J.-K.; Sunkar, R. Gene Regulation During Cold Stress Acclimation in Plants. Methods Mol. Biol. 2010, 639, 39-55. [CrossRef]

32. Zhu, J.; Dong, C.H.; Zhu, J.K. Interplay between cold-responsive gene regulation, metabolism and RNA processing during plant cold acclimation. Curr. Opin. Plant Biol. 2007, 10, 290-295. [CrossRef]

33. Miura, K.; Shiba, H.; Ohta, M.; Kang, S.W.; Sato, A.; Yuasa, T.; Iwaya-Inoue, M.; Kamada, H.; Ezura, H. SIICE1 encoding a MYC-type transcription factor controls cold tolerance in tomato, Solanum lycopersicum. Plant Biotechnol. 2012, 29, 253-260. [CrossRef]

34. Dieleman, J.A.; Heuvelink, E. Factors affecting the number of leaves preceding the first inflorescence in the tomato. J. Hortic. Sci. 1992, 67, 1-10. [CrossRef]

35. Khayat, E.; Ravad, D.; Zieslin, N. The effects of various night-temperature regimes on the vegetative growth and fruit production of tomato plants. Sci. Hortic. 1985, 27, 9-13. [CrossRef]

36. Nieuwhof, M.; Keizer, L.; Van Oeveren, J. Effects of temperature on growth and development of adult plants of genotypes of tomato (Lycopersicon esculentum Mill.). J. Genet. Breed 1997, 50, 185-193.

37. Venema, J.H.; Posthumus, F.; van Hasselt, P.R. Impact of Suboptimal Temperature on Growth, Photosynthesis, Leaf Pigments and Carbohydrates of Domestic and High-altitude Wild Lycopersicon Species. J. Plant Physiol. 1999, 155, 711-718. [CrossRef]

38. Améglio, T.; Cochard, H.; Ewers, F.W. Stem diameter variations and cold hardiness in walnut trees. J. Exp. Bot. 2001, 52, 2135-2142. [CrossRef] [PubMed]

39. Calvert, A. Effect of the Early Environment on the Development of Flowering in Tomato II. Light and Temperature Interactions. J. Hortic. Sci. 1959, 34, 154-162. [CrossRef]

40. Phatak, S. Top and root temperature effects on tomato flowering. J. Am. Soc. Hortic. Sci. 1966, 88, 527-531.

41. Fernandez-Muñoz, R.; Cuartero, J. Effects of temperature and irradiance on stigma exsertion, ovule viability and embryo development in tomato. J. Hortic. Sci. 1991, 66, 395-401. [CrossRef]

42. Li, J.; Ji, L. Adjusting multiple testing in multilocus analyses using the eigenvalues of a correlation matrix. Heredity 2005, 95, 221-227. [CrossRef] [PubMed]

43. Mata-Nicolás, E.; Montero-Pau, J.; Gimeno-Paez, E.; Garcia-Carpintero, V.; Ziarsolo, P.; Menda, N.; Mueller, L.A.; Blanca, J.; Cañizares, J.; Knaap, E.V.D.; et al. Exploiting the diversity of tomato; the development of a phenotypically and genetically detailed germplasm collection. Hortic. Res. 2020, 7, 66. [CrossRef] [PubMed] 